\title{
Is there any Link Between Vitamin D and Recurrence of Atrial Fibrillation after Cardioversion?
}

Belma Yaman ${ }^{1}$, MD; Levent Cerit ${ }^{1}$, MD; Hatice Kemal Günsel ${ }^{1}$, MD; Zeynep Cerit ${ }^{3}$, MD; Songül Usalp ${ }^{1}$, MD; Ümit Yüksek' , MD; Uğur Coşkun², MD; Hamza Duygu' ' MD; Onur Akpınar ${ }^{1}$, MD

\begin{abstract}
Introduction: Atrial fibrillation (AF) is the most common chronic arrhythmia in the elderly population. In symptomatic patients, restoration and maintenance of sinus rhythm improve quality of life. Unfortunately, AF recurrence still occurs in a considerable number of patients after cardioversion (CV). In this study, we aimed to evaluate the association between vitamin $D$ (VitD) and $A F$ recurrence after electrical or medical $C V$.

Method: A total of 51 patients who underwent CV for symptomatic AF were included in the study. AF recurrence was defined as an AF pattern in 12-lead electrocardiography (ECG) recording after CV within 6 months or ECG Holter recording of AF lasting more than $\mathbf{3 0}$ seconds at 6-month follow-up.

Results: Mean vitD level was $21.4 \mathrm{ng} / \mathrm{ml}$ in our study population. VitD level was lower in the AF recurrence group than in the non-
\end{abstract}

recurrence group ( $18 \mathrm{ng} / \mathrm{ml}$ vs. $26.3 \mathrm{ng} / \mathrm{ml}$, respectively; $P=0.001$ ). Additionally, left atrial diameter was larger in the AF recurrence group compared to the non-recurrence group (4.4 vs. 4.1, $P=0.025$ ). Patients with AF recurrence were older than patients without AF recurrence, and, although the prevalence of hypertension is higher in the AF recurrence group, there was no statistically significant difference $(P=0.107, P=0.867)$.

Conclusion: In our study, there is a strong association between vitD level and AF recurrence after CV. VitD deficiency might be a predictor of high risk of $A F$ recurrence after CV and vitD supplementation during the follow-up might help the maintenance of sinus rhythm.

Keywords: Atrial Fibrillation. Electric Countershock. Vitamin D. Prevalence. Quality of Life. Electrocardiography. Heart Atria. Hypertension.

\section{Abbreviations, acronyms \& symbols}

$\begin{array}{ll}\text { 2D } & =\text { Two-dimensional } \\ \text { AF } & =\text { Atrial fibrillation } \\ \text { BMI } & =\text { Body mass index } \\ \text { CAD } & =\text { Coronary artery disease } \\ \text { CV } & =\text { Cardioversion } \\ \text { DM } & =\text { Diabetes mellitus } \\ \text { ECG } & =\text { Electrocardiography } \\ \text { HT } & =\text { Hypertension }\end{array}$

\section{INTRODUCTION}

Atrial fibrillation (AF) is the most common chronic arrhythmia in the elderly population and associated with increased risk of stroke, high morbidity and mortality ${ }^{[1,2]}$. Although there are several risk factors for $A F$, such as hypertension (HT), diabetes mellitus (DM), heart failure (HF), older age, coronary artery disease

'Department of Cardiology, Near East Faculty of Medicine, Nicosia, Cyprus.

2Department of Cardiology, University of Kyrenia Faculty of Medicine, Kyrenia, Cyprus.

${ }^{3}$ Department of Pediatric Cardiology, Near East University, Nicosia, Cyprus.

This study was carried out at the Department of Cardiology, Near East Faculty of Medicine, Nicosia, Cyprus.
(CAD), valvular heart disease and obesity, the aetiology of AF is still largely unknown ${ }^{[3,4]}$. Medical and electrical cardioversion (CV) are well-established treatment modalities to restore sinus rhythm in patients with $A F^{[5]}$. Several factors, including type of $A F$, patient comorbidities, structural heart disease, and anticoagulation status, should be considered deciding to perform CV ${ }^{[6]}$.

Correspondence Address:

Belma Yaman

iD https://orcid.org/0000-0003-1515-6801

Near East Hospital University Hospital, Near East Boulevard, Nicosia, Cyprus Zip code: 99138

E-mail: belmayaman@yahoo.com 
Restoration and maintenance of sinus rhythm improve quality of life in symptomatic patients. The procedural success of CV depends on age, AF duration, left atrial size, CAD and chronic pulmonary disease ${ }^{[7,8]}$. Smoking, CAD, sleep apnea syndromes and type of AF are associated with increased risk of AF recurrence ${ }^{[9]}$.

Vitamin D (vitD) is transformed into an active metabolite in kidney and liver and binds specific tissue receptors on intestines, bone and kidney to increase serum calcium level. VitD receptors are also found in cardiomyocytes, brain, vascular smooth muscle cells, endothelial cells, pancreas, prostate and skeletal muscles ${ }^{[10]}$. In recent years, vitD deficiency has been shown not only to increase the risk of skeletal system diseases, but also to have adverse effects on the cardiovascular system with regulating the renin-angiotensin-aldosterone system (RAAS) and inflammatory process. VitD regulates the expression of anti-inflammatory cytokines such as interleukin 10 (IL-10) and IL-6 $6^{[11]}$. Two of the above-mentioned mechanisms are thought to be responsible for the high risk of AF in patients with vitD deficiency. In the current literature, there are inconsistent results about the association between vitD and risk of $A F^{[12,13]}$.

In light of this knowledge, we aimed to evaluate the association between serum vitD level and risk of AF recurrence after electrical or medical CV.

\section{METHODS}

\section{Study Population}

Between September 2017 and October 2018, 52 retrospective patients were included in our study, admitted to our cardiology department with AF and rhythm control strategy, chosen for medical or electrical CV. Patients with thrombus in left atrial appendage or other cardiac chambers, severe mitral valve disease, obstructive sleep apnea syndrome, hyperthyroidism, acute coronary syndrome, and using any medication that could affect vitD levels were excluded from the study. Patients with permanent AF were also excluded. Transesophageal echocardiography (TEE) was performed in all patients before CV, regardless of taking anticoagulant treatment and AF duration. After a successful CV, patients were followed for six months with regard to AF recurrence. The study was approved by the local Ethics Committee, and all patients provided written informed consent.

A detailed medical history of each patient was compiled, including the history of DM, HT, hyperlipidemia, peripheral artery disease, smoking, alcohol use, family history of CAD and treatment history. The patients' height and weight in fasting were measured; body mass indexes (BMI) (weight/height in kg/ $\mathrm{m}^{2}$ ) were calculated. Fasting plasma glucose, total cholesterol, triglyceride, low-density lipoprotein cholesterol, high-density lipoprotein cholesterol, thyroid-stimulating hormone (TSH) and serum vitD levels were assayed in blood samples after 12 hours overnight fasting before CV.

\section{Echocardiographic Examination}

The two-dimensional (2D) transthoracic echocardiography and TEE were performed to all participants before CV with available system (Vivid E9 system; General Electric Healthcare, Milwaukee, Wisconsin, USA). Standard 2D echocardiographic measurements were taken according to the guidelines of the American Society of Echocardiography and the European Society of Echocardiography ${ }^{[14]}$. Spontaneous echo contrast left atrial appendage thrombus and pulse wave velocities of left atrial appendage were evaluated by TEE.

\section{Definition of AF}

Paroxysmal atrial fibrillation (PAF) is defined as an episode of $A F$, which ends with electrical or medical CV in less than seven days. Persistent AF is defined as an AF, which occurs longer than seven days and ends with $\mathrm{CV}^{[13]}$. Routine electrocardiography (ECG) was performed at each visit, and 24-hour ECG Holter monitoring was scheduled for the 6-month follow-up visit. AF recurrence is defined as an AF pattern in 12-lead ECG recording after CV within 6 months or lasting more than 30 seconds of AF attacks in ECG Holter recording at 6 months of follow-up.

\section{Cardioversion}

Medical CV was preferred with amiodarone first with the regimen following the $300 \mathrm{mg}$ intravenous (IV) bolus over 30 to 60 minutes, $1000 \mathrm{mg}$ continuous IV infusion regimen up to 24 hours. The electrical CV was performed to non-responders of medical CV. Electrical CV was performed with patients in a fasting state under sedation and biphasic cardioverter-defibrillator devices between 50-200 Joules in synchronised mode. In patients with normal or low body mass index, the first shocks were done with 100 Joules, and, if the first shock is unsuccessful, the energy was increased. Also, in obese or over-weight patients, a higher energy shock was selected. To maintain sinus rhythm, amiodarone was added to treatment with 200 mg twice dayly after successful CV until hospital discharge.

\section{Statistical Analysis}

Data were analysed using SPSS software version 17.0 (SPSS, Chicago, IL, USA). Quantitative data were presented as mean \pm standard deviation. The Shapiro-Wilk test was used to test continuous variables for normality distribution. Student's t-test was used to evaluate continuous variables showing the normal distribution and Mann-Whitney U-test was used to evaluate variables that did not show normal distribution. Categorical variables were expressed as percentages. Chi-square test was used to compare categorical variables. Associations between serum vitamin D, AF recurrence, and other clinical parameters with regard to AF status were examined by univariable and multivariable logistic regression. A multivariable logistic regression model was used to derive odds ratio $(O R)$ for the risk of AF, so that each potential confounder variable with a $P$-value $\leq 0.10$ (based on univariable analysis) was entered. Statistical significance was defined as a $P$-value $<0.05$.

\section{RESULTS}

Fifty-two patients met the inclusion criteria and were included in the study; one patient was excluded due to lacking of laboratory data. Baseline characteristics of the randomised 
patients are listed in Table 1. There were 51 patients, with a mean age of 69.7 years, and $39.2 \%$ of them were female. Electrical CV was performed in $84.3 \%$ of the patients. After CV, the mean duration of the follow-up period was $6 \pm 2$ months. In our study, AF recurrence after CV was 58.8\% $(n=30)$.

Baseline clinical, echocardiographic and laboratory parameters were compared in AF recurrence group and nonrecurrence group in Table 2 . The comparison of AF recurrence according to serum vitD level, left atrial size and age were shown in Figure 1. Also, there is a negative correlation between vitD level and left atrial diameter in Figure $2(P=0.006, r=-0.376)$.

Left atrial diameter was larger in AF recurrence group when compared to the non-recurrence group $(4.4 \mathrm{~cm}$ vs. $4.1 \mathrm{~cm}$,

Table 1. Demographic features.

\begin{tabular}{|c|c|}
\hline Clinical parameters & Mean \pm SD \\
\hline Age (years) & $69.6 \pm 7.8$ \\
\hline Females, n (\%) & $20(39.2)$ \\
\hline HT, n (\%) & $26(51)$ \\
\hline $\mathrm{DM}, \mathrm{n}(\%)$ & $10(19.6)$ \\
\hline Smoking, n (\%) & $5(9.8)$ \\
\hline Hyperlipidemia, n (\%) & $6(11.8)$ \\
\hline CAD, n (\%) & $22(43.1)$ \\
\hline PAF, n (\%) & $43(84.3)$ \\
\hline CV (electrical), n (\%) & $43(84.3)$ \\
\hline Recurrence, n (\%) & $30(58.8)$ \\
\hline VitD replacement, n (\%) & $6(11.8)$ \\
\hline \multicolumn{2}{|l|}{ Echocardiographic parameters } \\
\hline LA diameter $(\mathrm{cm})$ & $4.36 \pm 0.5$ \\
\hline $\mathrm{LVH}, \mathrm{n}(\%)$ & $10(19.6)$ \\
\hline \multicolumn{2}{|l|}{ Laboratory parameters } \\
\hline Serum creatinine (mg/dl) & $0.92 \pm 0.2$ \\
\hline $\mathrm{TC}(\mathrm{mg} / \mathrm{dl})$ & $172.4 \pm 48.5$ \\
\hline $\mathrm{LDL}-\mathrm{C}(\mathrm{mg} / \mathrm{dl})$ & $104.3 \pm 38.6$ \\
\hline $\mathrm{HDL}-\mathrm{C}(\mathrm{mg} / \mathrm{d})$ & $41.9 \pm 10.9$ \\
\hline $\mathrm{TG}(\mathrm{mg} / \mathrm{dl})$ & $127.2 \pm 60.6$ \\
\hline Calcium (mg/dl) & $8.9 \pm 0.4$ \\
\hline $\mathrm{TSH}(\mathrm{mlU} / \mathrm{ml})$ & $1.5 \pm 0.8$ \\
\hline Vitamin B12 (pg/ml) & $468.3 \pm 307.8$ \\
\hline $25(\mathrm{OH}) \mathrm{VitD}(\mathrm{ng} / \mathrm{ml})$ & $21.4 \pm 9.0$ \\
\hline
\end{tabular}

$\mathrm{CAD}=$ coronary artery disease; $\mathrm{CV}=$ cardioversion; $\mathrm{DM}=$ diabetes mellitus; HDL-C=high-density lipoprotein cholesterol; HT=hypertension; LA=left atrium; LDL-C=lowdensity lipoprotein cholesterol; LVH=left ventricular hypertrophy; $\mathrm{PAF}=$ paroxysmal atrial fibrillation; $\mathrm{TC}=$ total cholesterol; $\mathrm{TG}=$ triglyceride; $\mathrm{TSH}=$ thyroid-stimulating hormone; VitD=vitamin D
$P=0.025)$. Patients with AF recurrence were older, and HT was frequently seen in the AF recurrence group; however, there was no statistically significant difference $(P=0.107, P=0.867$, respectively). The prevalence of PAF was $84.3 \%(n=43)$, persistent AF was $15.7 \%(n=8)$ in our study, and AF recurrence was similar between the two groups ( $P=0.581$ ). In addition, when comparing $\mathrm{CV}$ modalities, the prevalence of AF recurrence was higher in electrical CV group than in medical CV group; however, there was no statistically significant difference $(P=0.073)$. Comparison of baseline demographic features in electrical CV and medical CV groups was shown in Table 3.

The mean vitD level was $21.4 \mathrm{ng} / \mathrm{ml}$ in our study population. The vitD level was lower in the AF recurrence group than the non-recurrence group (18 ng/ml vs. $26.3 \mathrm{ng} / \mathrm{ml}, P=0.001)$. Receiver operating characteristic curve was used to explore the relationship between vitD level, which was measured before $\mathrm{CV}$ and AF recurrence after CV. The area under the curve was 0.745 . Using a cut-off level of $<22.0 \mathrm{ng} / \mathrm{ml}$, the pre-CV vitD level was associated with prediction of AF recurrence after CV with a sensitivity of $76.2 \%$ and specificity of $67.7 \%$ (Figure 3). Univariate and multivariate analysis of basal demographic features showed a correlation between vitD and AF recurrence after CV (Table 4).

\section{DISCUSSION}

In our study, lower serum vitD levels were found in the AF recurrence group, and vitD is an independent predictor of $A F$ recurrence after $C V$. Another finding of our study is that the left atrial size was larger in the AF recurrence group.

VitD deficiency is known to play a key role in the pathogenesis of $C A D$, left ventricular hypertrophy and $A F^{[11,15,16]}$. The vitD deficiency has been shown to be associated with left atrial fibrosis and increased risk of AF recurrence after ablation ${ }^{[17]}$. But this is the first study in the literature to evaluate the role of vitD deficiency in AF recurrence after CV.

The exact mechanisms of vitD deficiency in the cardiovascular system are not well-established. VitD has anti-oxidant and anti-inflammatory effects with regulating anti-inflammatory cytokines, including $\mathrm{IL}-10$ and $\mathrm{IL}-6^{[18,19]}$. Besides that regulating calcium metabolism, vitD has electromechanical effects in the left atrium ${ }^{[20]}$. The link between vitD deficiency and development of $A F, C A D$ and $H T$ is explained with the decrease of antiinflammatory effects in cardiac myocytes. Structural, electrical and contractile functions play a role in AF development. Left atrial fibrosis is the main mechanism of structural remodelling which progresses to AF. The association between left atrial fibrosis and vitD was found in a previous study by Canpolat et al. ${ }^{[17]}$. Oxidative stress, inflammation, and RAAS activation are the main mechanisms responsible for atrial fibrosis and might be associated with AF recurrence after ablation in patients with vitD deficiency ${ }^{[21]}$. Additionally, preoperative vitD supplementation could prevent postoperative AF after coronary artery bypass surgery ${ }^{[22]}$.

$\mathrm{CV}$ is the main treatment modality in symptomatic AF patients. AF ablation is another treatment modality to maintain sinus rhythm. After CV and ablation, a large part of patients fails to maintain sinus rhythm at follow-up ${ }^{[23]}$. AF type is the most important factor in predicting AF recurrence, such as permanent 
Table 2. Comparison of baseline demographic features in AF recurrence or non-recurrence groups.

\begin{tabular}{|c|c|c|c|}
\hline & $\begin{array}{l}\text { Recurrence } \\
\qquad(n=30)\end{array}$ & $\begin{array}{l}\text { Non-recurrence } \\
\qquad(n=21)\end{array}$ & $P$-value \\
\hline Age (years) & 71.1 & 67.4 & 0.107 \\
\hline Females, n (\%) & $13(43.3)$ & $7(33.3)$ & 0.472 \\
\hline $\mathrm{HT}, \mathrm{n}(\%)$ & $15(50)$ & $11(52.4)$ & 0.867 \\
\hline $\mathrm{DM}, \mathrm{n}(\%)$ & $4(13.3)$ & $6(28.6)$ & 0.177 \\
\hline Smoking, n (\%) & $3(10)$ & $2(9.5)$ & 0.955 \\
\hline Hyperlipidemia, n (\%) & $4(13.3)$ & $2(9.5)$ & 0.678 \\
\hline$C A D, n(\%)$ & $12(40)$ & $10(47.6)$ & 0.589 \\
\hline PAF, n (\%) & $26(86.7)$ & $17(81)$ & 0.581 \\
\hline Electrical cardioversion, n (\%) & $23(76.7)$ & $20(95.2)$ & 0.073 \\
\hline $\mathrm{LVH}, \mathrm{n}(\%)$ & $5(16.7)$ & $5(23.8)$ & 0.527 \\
\hline LA diameter $(\mathrm{cm})$ & 4.4 & 4.1 & 0.025 \\
\hline Serum creatinine $(\mathrm{mg} / \mathrm{dl})$ & 0.8 & 0.9 & 0.139 \\
\hline $\mathrm{TC}(\mathrm{mg} / \mathrm{dl})$ & 171.9 & 173.2 & 0.929 \\
\hline $\mathrm{LDL}-\mathrm{C}(\mathrm{mg} / \mathrm{dl})$ & 104.7 & 103.7 & 0.929 \\
\hline $\mathrm{HDL}-\mathrm{C}(\mathrm{mg} / \mathrm{dl})$ & 40.4 & 44.1 & 0.322 \\
\hline $\mathrm{TG}(\mathrm{mg} / \mathrm{dl})$ & 128 & 126.9 & 0.950 \\
\hline Calcium (mg/dl) & 8.8 & 9.1 & 0.114 \\
\hline $\mathrm{TSH}(\mathrm{mlU} / \mathrm{ml})$ & 1.6 & 1.3 & 0.328 \\
\hline Vitamin B12 (pg/ml) & 456.9 & 485.5 & 0.764 \\
\hline $25(\mathrm{OH})$ VitD (ng/ml) & 18 & 26.3 & 0.001 \\
\hline
\end{tabular}

$\mathrm{CAD}=$ coronary artery disease; $\mathrm{DM}=$ diabetes mellitus; $\mathrm{HDL}-\mathrm{C}=$ high-density lipoprotein cholesterol; $\mathrm{HT}=$ hypertension; $\mathrm{LA}=$ left atrium; LDL-C=low-density lipoprotein cholesterol; LVH=left ventricular hypertrophy; PAF=paroxysmal atrial fibrillation; $\mathrm{TC}=$ total cholesterol; TG=triglyceride; TSH=thyroid-stimulating hormone; VitD=vitamin D.

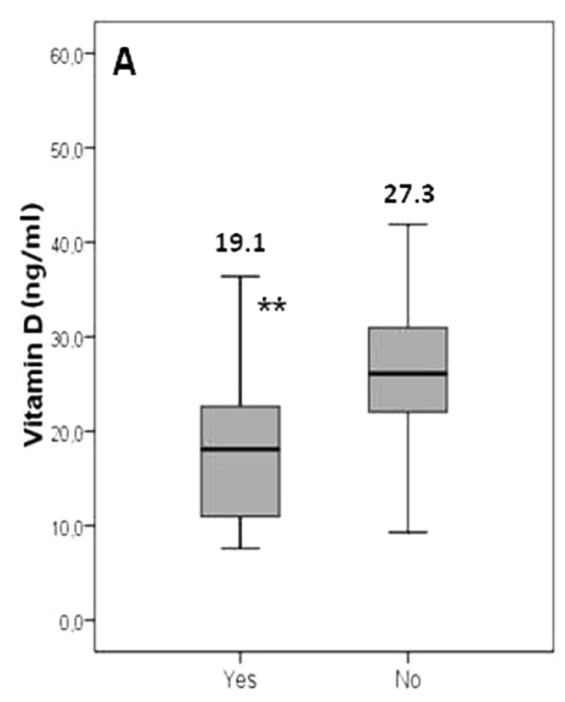

Recurrrence

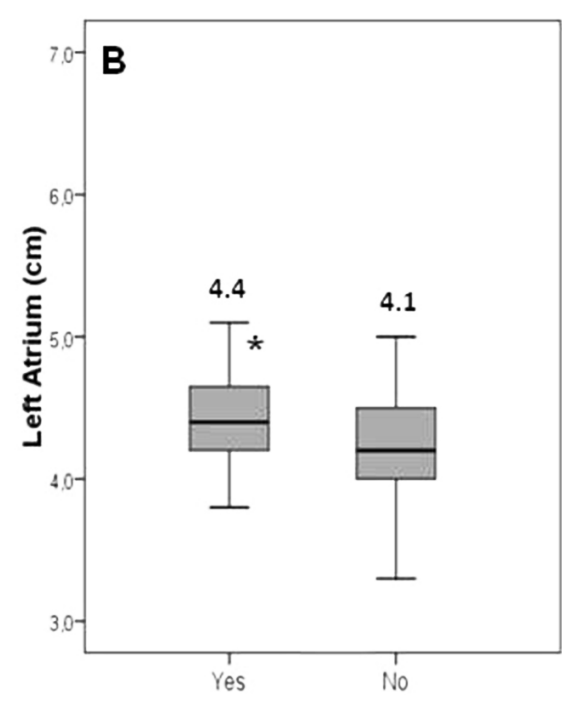

Recurrrence

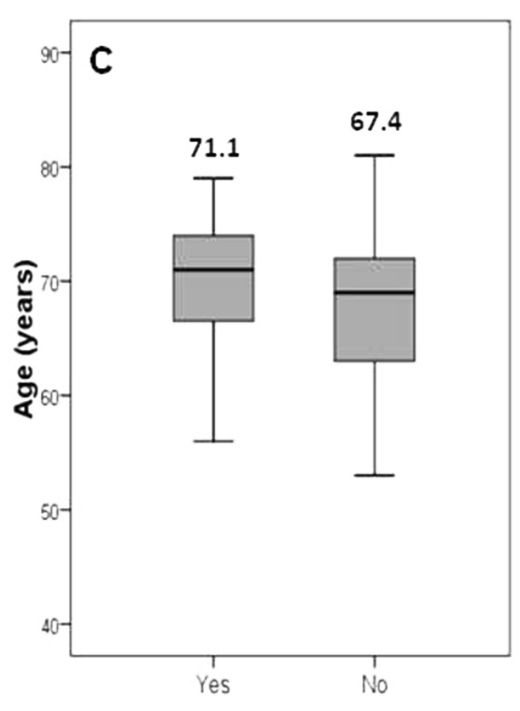

Recurrrence

Fig. 1 - The box-plot graph shows the comparison of atrial fibrillation recurrence according to serum $25(\mathrm{OH})$ VitD level $(A)$, left atrium size (B), and age $(C) .{ }^{*} P<0.05,{ }^{*} P<0.01$. 


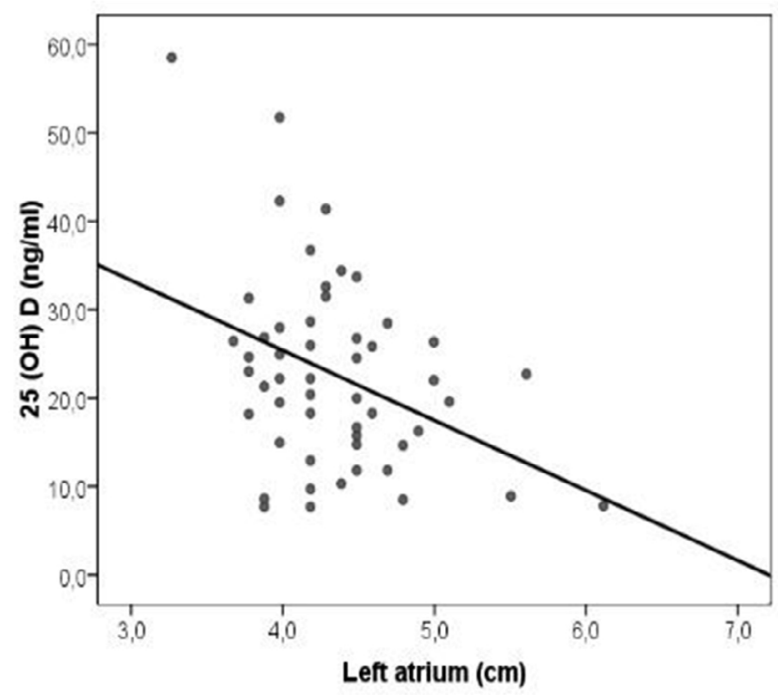

Fig. 2 - Correlation analysis shows a signficantly negative correlation between left atrial diameter and $25(\mathrm{OH})$ VitD level.

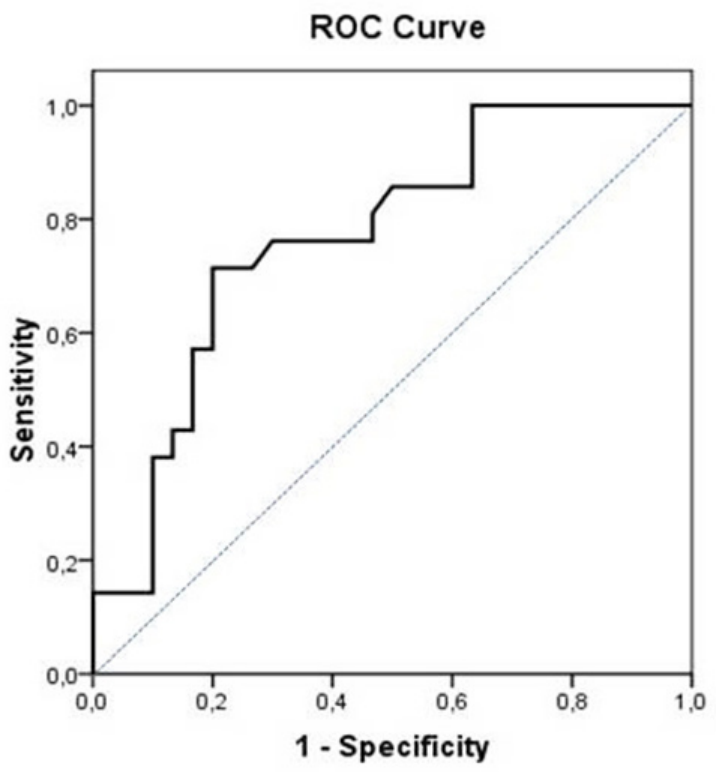

Fig. 3 - The receiver operating characteristic curve represents the cut-off point of $25(\mathrm{OH})$ VitD level in predicting AF recurrence after $C \mathrm{~V}$.

Table 3. Comparison of baseline demographic features in the electrical CV and medical CV groups.

\begin{tabular}{|c|c|c|c|}
\hline & $\begin{array}{l}\text { Electrical CV } \\
\qquad(n=43)\end{array}$ & $\begin{array}{c}\text { Medical CV } \\
\quad(n=8)\end{array}$ & $P$-value \\
\hline Age (years) & 69.3 & 71.2 & 0.635 \\
\hline Female gender, n (\%) & $14(32.6)$ & $6(75)$ & 0.024 \\
\hline HT, n (\%) & $23(53.5)$ & $3(37.5)$ & 0.406 \\
\hline $\mathrm{DM}, \mathrm{n}(\%)$ & $8(18.6)$ & $2(25)$ & 0.676 \\
\hline Smoking, n (\%) & $4(9.3)$ & $1(12.5)$ & 0.780 \\
\hline Hyperlipidemia, n (\%) & $5(11.6)$ & $1(12.5)$ & 0.944 \\
\hline CAD, n (\%) & $21(48.8)$ & $1(12.5)$ & 0.057 \\
\hline Paroxysmal AF, n (\%) & $36(83.7)$ & $7(87.5)$ & 0.787 \\
\hline $\mathrm{LVH}, \mathrm{n}(\%)$ & $8(18.6)$ & $2(25)$ & 0.676 \\
\hline LA diameter $(\mathrm{cm})$ & 4.3 & 4.4 & 0.606 \\
\hline Serum creatinine $(\mathrm{mg} / \mathrm{dl})$ & 0.9 & 0.7 & 0.058 \\
\hline $\mathrm{TC}(\mathrm{mg} / \mathrm{dl})$ & 170.1 & 182.6 & 0.414 \\
\hline $\mathrm{LDL}-\mathrm{C}(\mathrm{mg} / \mathrm{dl})$ & 104 & 105.6 & 0.726 \\
\hline $\mathrm{HDL}-\mathrm{C}(\mathrm{mg} / \mathrm{dl})$ & 40.3 & 48.7 & 0.498 \\
\hline $\mathrm{TG}(\mathrm{mg} / \mathrm{dl})$ & 124.4 & 141.1 & 0.515 \\
\hline Calcium (mg/dl) & 9.0 & 8.9 & 0.135 \\
\hline $\mathrm{TSH}(\mathrm{mlU} / \mathrm{ml})$ & 1.4 & 1.9 & 0.934 \\
\hline Vitamin B12 (pg/ml) & 496.1 & 339.7 & 0.095 \\
\hline $25(\mathrm{OH}) \mathrm{VitD}(\mathrm{ng} / \mathrm{ml})$ & 21.8 & 19.4 & 0.103 \\
\hline AF recurrence $\mathrm{n}(\%)$ & $23(53.5)$ & $7(87.5)$ & 0.073 \\
\hline
\end{tabular}

$\mathrm{AF}=$ atrial fibrillation; $\mathrm{CAD}=$ coronary artery disease; $\mathrm{CV}=$ cardioversion; $\mathrm{DM}=$ diabetes mellitus; $\mathrm{HDL}-\mathrm{C}=$ high density lipoprotein cholesterol; $\mathrm{HT}=$ hypertension; LA=left atrium; LDL-C=low density lipoprotein cholesterol; LVH=left ventricular hypertrophy; $\mathrm{TC}=$ total cholesterol; $\mathrm{TG}=$ triglyceride; $\mathrm{TSH}=$ thyroid-stimulating hormone; VitD=vitamin D 
Table 4. Univariate and multivariate analysis of baseline demographic features.

\begin{tabular}{l|c|c|c|c|c|c}
\hline \multirow{2}{*}{} & \multicolumn{3}{|c|}{ Univariate } & \multicolumn{3}{c}{ Multivariate } \\
\cline { 2 - 6 } & B & SE & $\boldsymbol{P}$ & B & SE & P \\
\hline Age (years) & -0.70 & 0.48 & 0.149 & & & \\
\hline LA diameter $(\mathrm{cm})$ & -1.213 & 0.873 & 0.165 & & & \\
\hline Serum creatinine $(\mathrm{mg} / \mathrm{dl})$ & 3.117 & 2.026 & 0.124 & & & \\
\hline $25(\mathrm{OH})$ VitD $(\mathrm{ng} / \mathrm{ml})$ & 0.100 & 0.046 & 0.031 & 0.121 & 0.042 & 0.004 \\
\hline
\end{tabular}

$\mathrm{LA}=$ left atrium; $\mathrm{Vit} \mathrm{D}=$ vitamin $\mathrm{D}$

$A F$, with a high risk of AF recurrence after ablation; however, patient characteristics such as age, sex, HT, smoking, and CAD were not associated with AF recurrence after AF ablation ${ }^{[9]}$. In our study, although HT and advanced age are associated with AF recurrence after $C V$, there was no statistically significant difference. Besides that, obstructive sleep disorder may cause AF recurrence after CV or ablation with several mechanisms, such as nocturnal hypoxemia and sympathetic nervous system activity, which can activate atrial stretching and diastolic dysfunction ${ }^{[24]}$. Patients with obstructive sleep apnea syndrome were excluded from our study.

Left atrial size was also shown to be an important factor in predicting AF recurrence. Patients with left atrial size greater than $4 \mathrm{~cm}$ have a higher AF recurrence risk ${ }^{[25]}$. In our study, the mean left atrial diameter was $4.4 \mathrm{~cm}$ in the recurrence group, which was significantly larger than in the non-recurrence group.

\section{Limitations}

Our study results should be evaluated as a part of several limitations; first, patients were taking different types of antiarrhythmic drugs; there was no homogenization in drug classes, which may affect the AF recurrence. Second, the duration between the first diagnosis of AF to CV is unknown in the paroxysmal AF group. Third, we did not take a blood sample for vitD and perform control echocardiography at six months of follow-up. The small sample size is another limitation of the study.

\section{CONCLUSION}

Lower vitD levels are associated with increased risk of AF recurrence after $C V$. Due to the close association between vitD deficiency and increased risk of AF recurrence, considering vitD levels before CV might be beneficial for the maintenance of sinus rhythm, and the vitD replacement in patients with vitD deficiency may prevent AF recurrence after CV.

\section{ACKNOWLEDGEMENT}

We thank all the physicians and nurses involved in this study.

No financial support.

\section{No conflict of interest.}

\section{Authors' roles \& responsibilities}

BY Substantial contributions to the conception or design of the work; or the acquisition, analysis, or interpretation of data for the work; drafting the work or revising it critically for important intellectual content; final approval of the version to be published

LC Substantial contributions to the conception or design of the work; drafting the work or revising it critically for important intellectual content; final approval of the version to be published

HK Substantial contributions to the conception or design of the work; or the acquisition, analysis, or interpretation of data for the work; drafting the work or revising it critically for important intellectual content; final approval of the version to be published

ZC The acquisition, analysis, or interpretation of data for the work; drafting the work or revising it critically for important intellectual content; final approval of the version to be published

SU The acquisition, analysis, or interpretation of data for the work; drafting the work or revising it critically for important intellectual content; final approval of the version to be published

UY Substantial contributions to the conception or design of the work; or the acquisition, analysis, or interpretation of data for the work; drafting the work or revising it critically for important intellectual content; final approval of the version to be published

UC Substantial contributions to the conception or design of the work; drafting the work or revising it critically for important intellectual content; final approval of the version to be published

HD Substantial contributions to the conception or design of the work; drafting the work or revising it critically for important intellectual content; final approval of the version to be published

OA Substantial contributions to the conception or design of the work; drafting the work or revising it critically for important intellectual content; final approval of the version to be published

\section{REFERENCES}

1. Benjamin EJ, Wolf PA, D'Agostino RB, Silbershatz H, Kannel WB, Levy D. Impact of atrial fibrillation on the risk of death: the Framingham heart study. Circulation. 1998;98(10):946-52. doi:10.1161/01.cir.98.10.946.

2. Stewart S, Hart CL, Hole DJ, McMurray JJ. A population-based study of 
the long-term risks associated with atrial fibrillation: 20-year follow-up of the Renfrew/Paisley study. Am J Med. 2002;113(5):359-64. doi:10.1016/ s0002-9343(02)01236-6

3. Benjamin EJ, Levy D, Vaziri SM, D'Agostino RB, Belanger AJ, Wolf PA. Independent risk factors for atrial fibrillation in a population-based cohort. The Framingham heart study. Jama. 1994;271(11):840-4. doi:10.1001/ jama.1994.03510350050036.

4. Heeringa J, van der Kuip DA, Hofman A, Kors JA, van Herpen G, Stricker BH, et al. Prevalence, incidence and lifetime risk of atrial fibrillation: the Rotterdam study. Eur Heart J. 2006;27(8):949-53. doi:10.1093/eurheartj/ehi825.

5. Meinertz T, Kirch W, Rosin L, Pittrow D, Willich SN, Kirchhof $P$, et al. Management of atrial fibrillation by primary care physicians in Germany: baseline results of the ATRIUM registry. Clin Res Cardiol. 2011;100(10):897905. doi:10.1007/s00392-011-0320-5.

6. Bonfanti L, Annovi A, Sanchis-Gomar F, Saccenti C, Meschi T, Ticinesi A, et al. Effectiveness and safety of electrical cardioversion for acute-onset atrial fibrillation in the emergency department: a real-world 10-year single centre experience. Clin Exp Emerg Med. 2019;6(1):64-9. doi:10.15441/ceem.17.286.

7. Joglar JA, Kowal RC. Electrical cardioversion of atrial fibrillation. Cardiol Clin. 2004;22(1):101-11.

8. Alt E, Ammer R, Lehmann G, Pütter K, Ayers GM, Pasquantonio J, et al. Patient characteristics and underlying heart disease as predictors of recurrent atrial fibrillation after internal and external cardioversion in patients treated with oral sotalol. Am Heart J. 1997;134(3):419-25. doi:10.1016/s00028703(97)70076-0.

9. Balk EM, Garlitski AC, Alsheikh-Ali AA, Terasawa T, Chung M, Ip S. Predictors of atrial fibrillation recurrence after radiofrequency catheter ablation: a systematic review. J Cardiovasc Electrophysiol. 2010;21:1208-16. doi:10.1111/ j.1540-8167.2010.01798.x.

10. Dusso AS, Brown AJ, Slatopolsky E. Vitamin D. Am J Physiol Renal Physiol. 2005;289(1):F8-28. doi:10.1152/ajprenal.00336.2004.

11. Vacek JL, Vanga SR, Good M, Lai SM, Lakkireddy D, Howard PA. Vitamin D deficiency and supplementation and relation to cardiovascular health. Am J Cardiol. 2012;109(3):359-63. doi:10.1016/j.amjcard.2011.09.020.

12. Demir M, Uyan U, Melek M. The effects of vitamin D deficiency on atrial fibrillation. Clin Appl Thromb Hemost. 2014;20(1):98-103. doi:10.1177/1076029612453762.

13. Rienstra M, Cheng S, Larson MG, McCabe EL, Booth SL, Jacques PF, et al. Vitamin D status is not related to development of atrial fibrillation in the community. Am Heart J. 2011;162(3):538-41. doi:10.1016/j.ahj.2011.06.013.
14. Lang RM, Bierig M, Devereux RB, Flachskampf FA, Foster E, Pellikka PA, et al. Recommendations for chamber quantification. Eur J Echocardiogr. 2006;7(2):79-108. doi:10.1016/j.euje.2005.12.014.

15. Pittas AG, Dawson-Hughes B, Li T, Van Dam RM, Willett WC, Manson JE, et al. Vitamin D and calcium intake in relation to type 2 diabetes in woman. Diabetes Care. 2006;29(3):650-6. doi:10.2337/diacare.29.03.06.dc05-1961.

16. Zhang Z, Yang Y, Ng CY, Wang D, Wang J, Li G, et al. Meta-analysis of vitamin D deficiency and risk of atrial fibrillation. Clin Cardiol. 2016;39(9):537-43. doi:10.1002/clc.22563.

17. Canpolat U, Aytemir K, Hazirolan T, Ozer N, Oto A. Relationship between vitamin $\mathrm{D}$ level and left atrial fibrosis in patients with lone paroxysmal atrial fibrillation undergoing cryoballoon-based catheter ablation. J Cardiol. 2017;69(1);16-23. doi:10.1016/j.jjcc.2016.06.012.

18. Li YC, Kong J, Wei M, Chen ZF, Liu ZQ, Cao LP. 1,25-Dihydroxivitamin D(3) is a negative endocrine regulator of the renin-angiotensin system. J Clin Invest. 2002:110(2):229-38. doi:10.1172/JCl15219.

19. van Etten E, Mathieu C. Immunoregulation by 1,25-Dihydroxivitamin D3: basic concepts. J Steroid Biochem Mol Biol. 2005;97(1-2):93-101. doi:10.1016/j.jsbmb.2005.06.002.

20. Hanafy DA, Chang SL, Lu YY, Chen YC, Kao YH, Huang JH, et al. Electromechanical effects of 1,25-dihydroxyvitamin d with antiatrial fibrillation activities. J Cardiovasc Electrophysiol. 2014;25(3):317-23. doi:10.1111/jce.12309.

21. Pellman J, Lyon RC, Sheikh F. Extracellular matrix remodelling in atrial fibrosis: mechanisms and implications in atrial fibrillation. J Mol Cell Cardiol. 2010;48(3):461-7. doi:10.1016/j.yjmcc.2009.09.001.

22. Cerit L, Özcem B, Cerit Z, Duygu H. Preventive effect of preoperative vitamin D supplementation on postoperative atrial fibrillation. Braz J Cardiovasc Surg. 2018;33(4):347-52. doi:10.21470/1678-9741-2018-0014.

23. Aytemir K, Oto A, Canpolat U, Sunman H, Yorgun H, Şahiner L, et al. Immediate and medium-term outcomes of cryoballoon-based pulmonary vein isolation in patients with paroxysmal and persistent atrial fibrillation: single-centre experience. J Interv Card Electrophysiol. 2013;38(3):187-95. doi:10.1007/ s10840-013-9834-2.

24. Verrier RL, Josephson ME. Impact of sleep on arrhytmogenesis. Circ Arrhythm Electrophysiol 2009;2(4):450-9. doi:10.1161/CIRCEP.109.867028.

25. Cerit L, Kemal H, Gulsen K, Ozcem B, Cerit Z, Duygu H. Relationship between Vitamin $D$ and the development of atrial fibrillation after on-pump coronary artery bypass graft surgery. Cardiovasc J Afr. 2017;28(2):104-7. doi:10.5830/ CVJA-2016-064. 